\title{
Retrobulbar hemorrhage associated with subarachnoid hemorrhage
}

\author{
Şahin Çolak ${ }^{\mathrm{a}}$, Mehmet Özgür Erdoğan ${ }^{\mathrm{a}^{*}}$, Latif Duran ${ }^{\mathrm{b}}$, Celal Katı ${ }^{\mathrm{b}}$, Ahmet Şenel ${ }^{\mathrm{a}}$ \\ ${ }^{a}$ Department of Emergency Medicine, Haydarpaşa Numune Training and Research Hospital, Istanbul, Turkey \\ ${ }^{b}$ Department of Emergency Medicine, Faculty of Medicine, Ondokuz Mayis University, Samsun, Turkey
}

\section{ARTICLE INFO}

\section{ABSTRACT}

\section{Article History}

Received

27 / 08 / 2013

Accepted

$08 / 10 / 2013$

\section{* Correspondence to:}

Mehmet Özgür Erdoğan

Department of Emergency Medicine,

Haydarpaşa Numune Training and Research

Hospital, Istanbul, Turkey

e-mail: ozgurtheerdogan@mynet.com

\section{Keywords:}

Emergency

Propitosis

Retrobulbar hemorrhage

Subarachnoid hemorrhage
Retrobulbar haemorrhage is a rare emergency condition usually associated with trauma. Major clinical features are loss of visual acuity, eye pain and increasing propitosis. Several spontaneous cases were also reported in literature. We present a 36 years old case of a spontaneus retrobulbar haemorrhage associated with subarachnoid haemorrhage. Patient underwent a lateral canthotomy and cantholysis (LCC) and intravenous corticosteroids, mannitol, topical timolol and acetazolamide were administered. The aim of this study was to increase the awareness of retrobulbar haemorrhage in emergency staff. This will prevent the delay in treatment that will lead to the situation whereby the patient is left permanently blind. Retrobulbar haemorrhage is an ophtalmic acute surgical emergency that emergency physicians have to be familiar with.

J. Exp.Clin. Med., 2013; 30:373-375

\section{Introduction}

Retrobulbar hemorrhage $(\mathrm{RH})$ is a rare condition usually associated with trauma and iatrogenic origins (Allen et al., 2010). Several cases of spontaneous RH due to intraorbital aneurysm of the ophthalmic artery, venous anomalies, atherosclerosis, hemophilia and hypertension have been described in literature (Lima et al., 2009). Here, we present a spontaneous RH due to subarachnoid hemorrhage ( $\mathrm{SH})$. The aim of this report was to increase the level of awareness of $\mathrm{RH}$ and its treatment in emergency staff.

\section{Case}

A 36 years old man presented to emergency department (ED) with loss of consciousness. On arrival, patient's Glasgow Coma Scale score was three (E1M1V1) and paramedics were assisting his ventilations. Physical examination of patient revealed an arterial blood pressure of $60 / 40 \mathrm{mmHg}$ and pulse rate of 40 beats/min. After intubation, ED staff noted that patient's right eye was markedly hemorrhagic and proptotic. A tonometer was not available in emergency service, but right eye was firmer than left in physical examination (Fig. 1). Right eye also had afferent pupillary defect. His blood count and biochemical values were within normal range.

A computed tomography scan $(\mathrm{CT})$ revealed that increased intraocular pressure (IOP) and proptosis was due to RH (Fig. 2). Tomography scan also revealed diffuse SH (Fig. 3).

RH was treated with intravenous mannitol, prednisolone and topical timolol in the emergency service. Patient was transferred to intensive care unit (ICU). Urgent lateral canthotomy and cantholysis (LCC) was performed in ICU by an ophtalmologist. Patient died two hours after hospitalization. Cerebral angiography was not performed because of the instability of the patient.

\section{Discussion}

RH is an ophtalmic acute surgical emergency that ED physicians have to be familiar with (Lima et al., 2009). Major clinical features of disease are loss of visual acuity, eye pain and increasing propitosis (Hislop et al., 1996). 


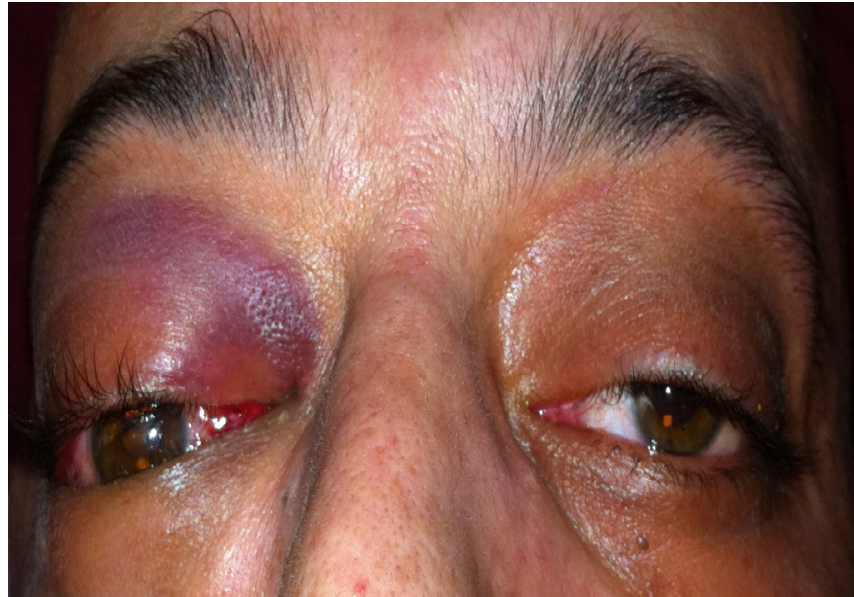

Fig. 1. Propitosis in the right eye.

Spontaneous RH due to $\mathrm{SH}$ has not been described in literature. Our case is the only report of this combination in literature. Unfortunately, patient could not be stabilized to perform angiography. Due to the lack of angiographic evidence, we can only suggest the possibility of an aneurysm with the existence of synchronous RH and SH (Yanaka et al., 2002; Chang et al., 2011).

Orbit has a limited potential to expand (Lima et al., 2009). Hemorrhage or edema may increase retroorbital pressure. Orbit compensates through propitosis but medial and lateral canthal tendons limit the move of globe. If orbital pressure exceeds the pressure of central retinal artery, retinal ischemia results (McInnes and Howes, 2002). Acute rise of orbital pressure due to hemorrhage may result in visual loss due to ischemia of optic nerve. Orbit has to be decompressed urgently to return to the previous visual acuity (Hislop et al., 1996). Generally, eye injuries need urgent treatment (Alagöz et al., 2006).

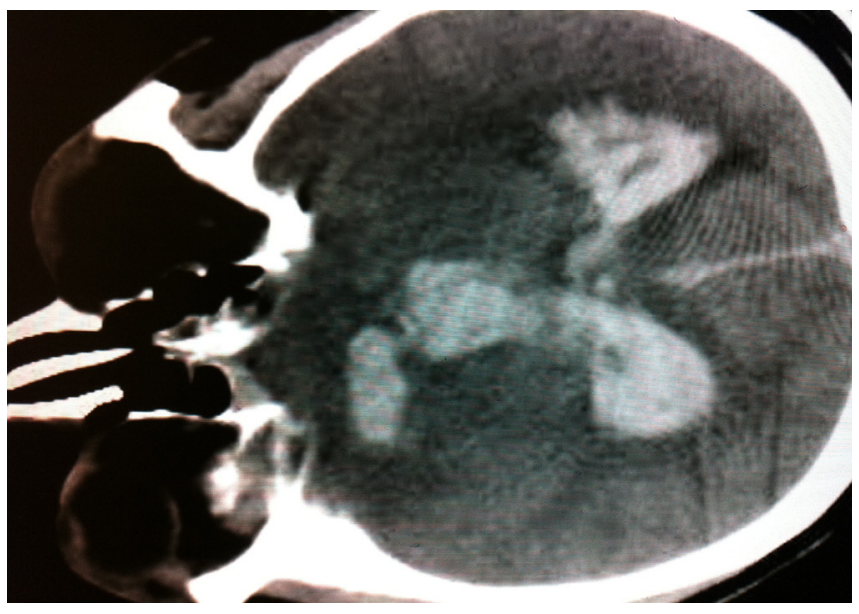

Fig. 2. Retrobulbar Hemorrhage in cranial tomography.

Recent studies show a time period of 90 minutes for decompression to return to the previous visual acuity (Hislop

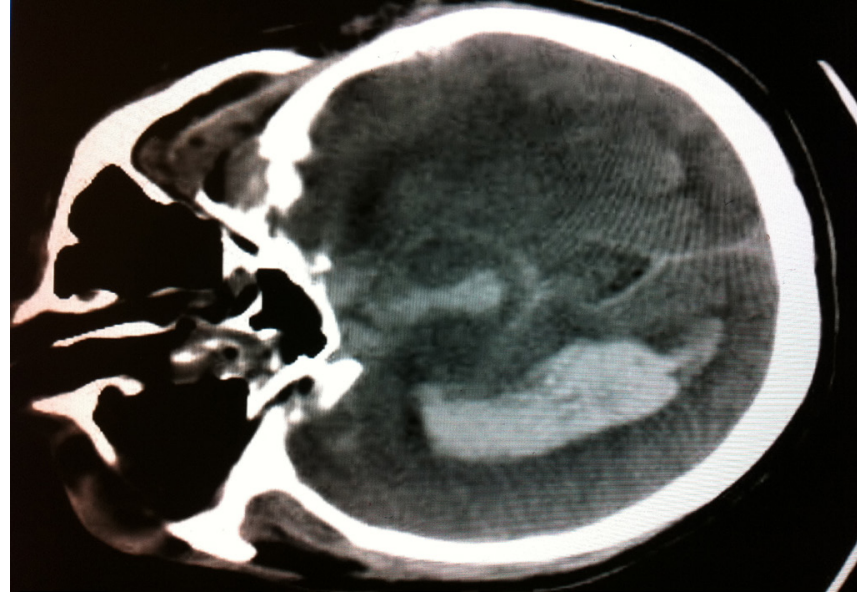

Fig. 3. Subarachnoid hemorrhage in cranial tomography.

et al., 1996). In our case, surgical intervention was performed approximately two hours after admission. This may be considered as a delay in treatment. We don't know the outcome of surgical intervention due to death of the patient. Our study raises a suspicion that $\mathrm{RH}$ may not be diagnosed and treated adequately in emergency services leading to the situation where patient is left permanently blind (Hislop et al., 1996). This underlines the need for early diagnosis and treatment.

Tonometry may be helpful in diagnosis of increased ocular pressure. Usually tonometry is not an available device in ED (McInnes and Howes, 2002). The normal range of ocular pressure is $8-21 \mathrm{mmHg}$ (Shek et al., 2006). An IOP higher than $40 \mathrm{mmHg}$ is sufficient for LCC in unconscious orbital trauma patients. If proptosis and loss of visual acuity and obvious globe compressibility difference exists, LCC should be performed urgently (McInnes and Howes, 2002). Any patient requiring urgent brain $\mathrm{CT}$, who has midfacial injuries or proptosis, should also undergo orbital imaging (Winterton et al., 2007; Akdur et al., 2009; Allen et al., 2010).

Recent studies suggest that combination of LCC with intravenous corticosteroids; mannitol, topical timolol and acetazolamide are the treatment of choice (Winterton et al., 2007). Mannitol and acetazolamide are used to decrease the intraocular pressure. Although acetazolamide has a delayed effect, mannitol's effect is immediate. Intravenous steroids are used to reduce the inflammation. Timolol decrease the aqueous humor production. Medical treatments were given to our patient before surgical intervention.

Medical treatment is straightforward and ED staff can urgently begin during stabilization of the patient. Current surgical procedure is easy and can be performed in emergency departments under local anesthesia (Winterton et al., 2007).

Retrobulbar hemorrhage is an ophtalmic acute surgical emergency that emergency department physician has to be familiar with. Prompt diagnosis is mandatory for adequate management of retrobulbar hemorrhage.

\section{REFERENCES}

Akdur, O., Özkan, S., Erkılıç, K., Durukan, P., Duman, A., İkizceli, İ., 2009. Evaluation of ocular trauma cases presentıng to the emergency department. JAEMCR. 8, 47-50.

Alagöz, G., Yıldırım, C., Durukan, P., İkizceli, İ., Besen, H., 2006. İş kazası sonucu oluşan kimyasal göz yanığı: Olgu Sunumu. Jaem. 4 , 35-36. Allen, M., Perry, M., Burns, F., 2010. When is a retrobulbar haemorrhage not a retrobulbar haemorrhage?. Int J Oral Maxillofac Surg. 39, 10451049.

Chang, J.H., Lee, D.K., Kim, B.T., Ohn, Y.H., 2011. Computed tomographic angiogram of an anterior communicating artery aneurysm causing 
acute retrobulbar optic neuropathy: A case report. Korean J. Ophthalmol. 25, 366-368.

Hislop, W.S., Dutton, G.N., Douglas, P.S., 1996. Treatment of retrobulbar haemorrhage in accident and emergency departments. Br. J. Oral Surg. 34, 289-292.

Lima, V., Burt, B., Leibovitch, I., Prabhakaran, V., Goldberg, R.A., Selva, D., 2009. Orbital Compartment Syndrome: The Ophthalmic Surgical Emergency. J. Survophthal. 54, 441-449.

McInnes, G., Howes, D.W., 2002. Lateral canthotomy and cantholysis: A simple, vision-saving procedure. CJEM. 4, 49-52.

Shek, K.C., Chung, K.L., Kam, C.W., Yau, H.H., 2006. Acute retrobulbar haemorrhage: An ophthalmic emergency. Emerg. Med. Australasia. $18,299-301$.

Winterton, J.V., Patel, K., Mizen, K.D., 2007. Review of management options for a retrobulbar hemorrhage. J. Oral Maxillofac. Surg. 65, 296299.

Yanaka, K., Matsumaru, Y., Kamezaki, T., Nose, T., 2002. Ruptured Aneurysm of the Ophthalmic Artery Trunk Demonstrated by ThreeDimensional Rotational Angiography: Case report. Neurosurgery. 51, 1066-1070. 